\title{
Interactive comment on "Ground subsidence and heave over permafrost: hourly time series reveal inter-annual, seasonal and shorter-term movement caused by freezing, thawing and water movement" by Stephan Gruber
}

\section{Anonymous Referee \#2}

Received and published: 18 March 2020

The manuscript by Gruber presents high-resolution measurements of ground subsidence and heave over permafrost soils at three different sites. A new measurement device has been developed and tested in order to measure these soil vertical movements.

Overall, the manuscript is well written and the flow is structured and coherent. The tiltarm device is well presented, and its potential limitations as well. The accompanying data of heave and ground subsidence are well explained. I encourage the author to make a short communication exclusively on this topic. 
One of the main unclear points of the manuscript is Figure 4 and the accompanying text, that must be rewritten. In particular, what does 'density' refer to ?

Some other details need to be addressed by the author, such as :

- Section 3 : Is it possible to add a picture and/or a satellite image of the studied sites ?

- Section 4.2 (auxiliary data) : Splitting soil temperature data section into a whole paragraph does not seem necessary. Could it be merged into section 4.1 ?

- Section 4.8 : paragraph not necessary. Could be removed, or used as a small introductory sentence for section 5

- Section 5.3 : How are defined the thawing and freezing seasons ? Soil temperatures, air temperatures, freezing indexes?

Moreover, some mathematical notations are unclear, and a few sentences need clarification. For instance :

- Line122 : 'at a distance of 10m or less' : I guess it is at a distance of the tilt-arm logger? Please precise.

-Line 172 : The wording 'during the time interval $[\mathrm{t}=0, \mathrm{t}]$ ' is unclear (and mathematically awkward) : does $z(t)$ simply denotes the thickness of soil thawed at the time $t$ ? If so, please remove the sentence 'during the time interval $[\mathrm{t}=0, \mathrm{t}]$ '.

- Line 178 : Should not it be 'proportional' instead of 'equal' in $z=\operatorname{sqrt}(\mathrm{I}(\mathrm{t}))$ ?

- Line 195 : extra parenthesis in the text (Fig.5)

Please check the annotations and remarks in the attached document.

Please also note the supplement to this comment:

https://www.the-cryosphere-discuss.net/tc-2019-227/tc-2019-227-RC2- 
supplement.pdf

Interactive comment on The Cryosphere Discuss., https://doi.org/10.5194/tc-2019-227, 2019.

Interactive

comment 